\title{
An Empirical Study of Problems in Implementation of Electronic Commerce in Kingdom of Saudi Arabia
}

\author{
Iftekhar Ahmad ${ }^{1} \&$ Anand Mohan Agrawal ${ }^{2}$ \\ ${ }^{1}$ Department of Management, Waljat College of Applied Sciences, Muscat, Oman \\ ${ }^{2}$ Birla Institute of Technology, Ranchi \& General Manager, Knowledge Initiative, Omzest, Muscat, Oman \\ Correspondence: Iftekhar Ahmad, Waljat College of Applied Sciences, P.O.Box-197, Rusayl, Postal Code-124, \\ KOM, Muscat, Oman. Tel: 968-9975-4819. E-mail: iftek.ahmad@gmail.com
}

Received: June 8, 2012

Accepted: June 15, 2012

Published: August 1, 2012

doi:10.5539/ijbm.v7n15p70

URL: http://dx.doi.org/10.5539/ijbm.v7n15p70

\begin{abstract}
This research paper has examined the statistical significance of various problems in implementation of e-commerce solution in business organizations in Kingdom of Saudi Arabia. KSA (Kingdom of Saudi Arabia) has witnessed substantial progress in the field of ICT related infrastructural development in the first decade of $21^{\text {st }}$ century. However, despite these positive developments and abundant resources, Kingdom of Saudi Arabia (KSA) in particular and GCC member countries in general have not been able to catch up with the pace of digital development in the rest of the world. The research paper attempts to identify the problems in implementing e-commerce in Kingdom of Saudi Arabia. This research paper on the basis of analysis of data through hierarchical multiple regression modeling and multiple response analysis of the data has identified statistically significant problems in implementation of e-commerce in Kingdom of Saudi Arabia and outlined key policy options that this country as well as other GCC nations can consider in formulation of policies to stimulate, support and maximize the effect e-commerce has on their economies.
\end{abstract}

Keywords: e-commerce, problems, Kingdom of Saudi Arabia, GCC, hierarchical multiple regression

\section{Introduction}

Rapid advancements in the field of information and telecommunications technologies in the first decade of $21^{\text {st }}$ century, have been truly remarkable and has resulted in amazing transformation of some societies (notably Western) into information-based cultures. Fast emergence and acceptance of e-commerce has resulted in effecting deep positive impact on business world. It is being implemented rapidly in business establishments in different sectors of the economy worldwide. Multi National Companies are early adopters of e-commerce. As these companies are conducting business in multiple countries and working through numerous supply chain components such as suppliers, original equipment manufacturers, dealers, importers and carry \& forward ( C\&F) agents, distributors and retailers etc., the coordination between these entities has become vital so as to be successful in the competitive environment. An integrated supply chain with a well designed e-commerce infrastructure has dramatically improved their performance and minimized costs.

The use and application of electronic commerce in business practices is quite varied between different parts of the world. There has been rapid growth in the use of e-commerce in North American continent, West Europe, South East Asian countries, while in Middle East Asia it has yet to see that level of growth. Kingdom of Saudi Arabia, which is the founding and the largest member of the Gulf Cooperation Council [GCC] provides an ideal context for analysis of the problems in E-Commerce development and implementation.

Kingdom of Saudi Arabia being one of the world's top 10 most competitive economies, is one of the perfect investment destination on the landscape of Middle East Asia. According to Saudi Arabia General Investment Authority, Kingdom of Saudi Arabia (KSA) is fast emerging world economic centre and various reports, rankings and indices related to business climate, free market, per capita income, purchasing power parity, market reforms, oil reserves, fiscal freedom etc., indicate in the same direction.

\subsection{Research Problem}

Despite all above positive indicators, electronic commerce is still in its early stages of implementation in 
Kingdom of Saudi Arabia (KSA). Electronic commerce solutions adoption and implementation are far from adequate in the entire in KSA. The problems faced by business sectors in implementation of ecommerce solutions are multi faceted. It is further compounded by cultural constraints, digital illiteracy, a vastly absent enabling environment, and the often limited awareness at decision-making levels of the importance of sound and forward-looking ICT policies and strategies as well as the potential for ICT applications.

\subsection{Study Objectives}

This study paper aims to achieve two specific objectives:

- To identify various problems faced by business establishments in implementing e-commerce solutions in Kingdom of Saudi Arabia

- To examine the statistical significance of these problems

\section{Review of Literature}

Review of the available literature shows that there is a paucity of writings focusing on the problems in implementing ecommerce solutions in business organization in GCC nations especially Kingdom of Saudi Arabia. In this part of the world, it is one of the most overlooked areas, where writings still focus on end-user computing, developing models for SMEs rather than analyzing of what has happened during implementation of e-commerce.

The existing literature on e-commerce was reviewed and it was found that most of the available literature are in bits and pieces and does not offer a holistic view of the problems (having statistical significance) affecting e-commerce implementation in Kingdom in Saudi Arabia. Almost negligible work has been done to examine the statistical significance of problems faced by organization in implementation of ecommerce in Kingdom of Saudi Arabia. The existing literature is typically characterized by the absence of not only the meta analysis but also the summary statistics as well. In the absence of any statistical analysis of large collection of analysis results from individual or institutional research on the above mentioned problem in Saudi Arabia offers a window of opportunity for this research. Up till 2004, almost negligible research was undertaken for assessment of e-commerce implementation results and analysis of problems that influence these results. Review of some of the available literature does throw some light.

Begin and Boisvert (2002) analyzed strategic factors that influence e-commerce implementation in Canada. They did a micro level study to identify these factors. In their study focus was to identify the developments within the organization that were influencing ecommerce implementation. External environment was completely ignored. They identified these factors similar to the strength an weakness elements (in SWOT analysis). It was described as internal factors or inhibitors. They have tried to classify the factors into groups which can serve as a good starting point to analyze these factors and identify their influence on e-commerce implementation results, however, the biggest limitation of this study was that it did not take into account any of the external factor and their study does include any statistical analysis of the problems that are affecting the implementation of e-commerce.

Teo, Chan, and Parker (2004) have done a meta analysis of literature related to factors affecting adoption of e-commerce specifically in small and medium enterprises. Existing literature shows that it was among the first few meta analysis of the factors affecting the implementation of e-commerce. They did identify the factors as highly complex and various mix of factors. However, their study concentrated on identifying specific factors and in the process ignored the holistic view of the problem. They have identified some meta factors from the available literatures, which are related to adoption of e-commerce. However, different literatures have conflicting viewpoints about these meta factors. In addition to this, none of these meta factors are related to measure the impact of e-commerce implementation results neither does it identify the major barriers in its implementation at business level.

Studies undertaken by Radovilsky and Hegde (2004) and Zhu (2004) were good efforts in this direction, however these studies were related to North America and it emphasized on the technological competence of the firm in the diffusion of e-commerce. It failed to identify the apparent and latent social, cultural other demographic obstacles in the implementation of e-commerce solution.

Study undertaken by Oreku, Mtenzi and Ali (2011), helps in identifying the important factors in implementation of electronic commerce however the study has been carried out in East Africa which has a very different cultural environment as compared to GCC. Most of the researchs in this field suggest that factors such as culture, economic condition, consumer behavior, purchasing power parity have direct bearing on the implementation of ecommerce. As there is substantial difference between east Africa and Kingdom of Saudi Arabia on economic, 
social and cultural parameters, hence its findings may not be applicable in this part of the world.

Another recent study by Al-Hudhaif and Alkubeyyer (2011) throw some light on the factors contributing to the adoption of ecommerce in Kingdom of Saudi Arabia. This is a good study however it focuses on the micro view of the adoption of e-commerce and does not take into account the holistic view of the surrounding. A horizontal study is required to identify the factors affecting the implementation of e-commerce across the industry sectors with a large sample size and subsequently another vertical study may be undertaken.

\subsection{Conclusion of Review of Literature}

On the basis of overall evaluation of available literature sources, it is evident that there is clear need of undertaking research to identify and analyze the factors that influence implementation of e-commerce solutions in various organizations. In this research, efforts are being taken to address the specified issues of establishing and analyzing such factors.

\section{Methodology}

This study is centered on examining different aspects of electronic commerce implementation results. And the objectives are to identify what are the major barriers and impediments in use and implementation of ecommerce solutions and secondly to examine the statistically significant relationship between two variables i.e., major obstacles in e-commerce implementation and e-commerce implementation results. Hence in the light of these two specifics, within the Quantitative paradigm, the methodology used are Cross Sectional Descriptive Research Design.

\subsection{Sampling Design}

The sample frame was obtained from a list representative of the entire market in KSA. Respondents were screened by the question "Do you use the Internet to buy, sell, or support products or services?" The final sample thus represents firms actually using the Internet for business, rather than the full population. Final sample size from KSA included 237 business establishments. Respondents were CIOs, CEOs, IS directors or IT managers, i.e., the people actually involved in key decisions about e-commerce implementation and use.

Stratified random sampling technique from the probability sampling method has been used in this research. The sample was stratified by firm size, in accordance with the OECD classification standards. Business establishments were distributed across three industry sectors that are considered leading users of the Internet and e-commerce. These were trading sector (wholesale/retail distribution), services sector and manufacturing sector and only those business establishments were considered where electronic commerce has been implemented.

From the strata based on company size, random numbers (The Rand Corporation, 1955) were allocated to each unit of the sampling frame and using simple random sampling technique, final sample was selected from each strata.

\subsubsection{Sample Size, Level of Precision, Confidence Level and Degree of Variation}

For determining sample size, mathematical formula developed by Yamane (1967) has been used. The original Yamane formula is as follows.....

Where:

$$
\text { SampleSize } \quad(n)=\frac{z^{2} P(1-P) N}{z^{2} P(1-P)+N\left(e^{2}\right)}
$$

$$
\begin{aligned}
& \mathrm{n}=\text { sample size } \\
& \mathrm{N}=\text { population size } \\
& \mathrm{e}=\text { the level of precision } \\
& \mathrm{z}=\text { the value of the standard normal variable given the chosen confidence level (e.g. } \mathrm{z}=1.96 \text { with a } \mathrm{CL} \\
& =95 \% \text { and } \mathrm{z}=2.57 \text { with a } \mathrm{CL}=99 \% \\
& \mathrm{P}=\text { the proportion or degree of variability }
\end{aligned}
$$

To understand the mathematical formula, we need to understand the major criteria for determining sample size. According to Miaoulis and Michener (1976) and others, three major criteria are usually taken into consideration for determining sample size. These three criteria are as follows...

1) Level of precision: decided to keep it at $\pm 5 \%$

2) Confidence Level: Confidence level was kept at $95 \%$ 
3) Degree of variability in the attributes being measured: 0.5

Calculated through above mathematical formulation, sample size for KSA was found to be 237 . The questions used in the questionnaire used both nominal well as ordinal scales. The final sample (sample size: 237) represents firms actually using the Internet for business, rather than the full population of firms in each country.

\subsection{Survey Instrument, Its Reliability and Validity Assessment}

The survey instrument was planned and designed on the basis of an extensive literature review and discussion with IT managers. Instrument in this research has been adapted from the original model instrument developed by OECD, the instruments designed by Kraemer et al (2006) and Radovilsky \& Hegde (2004) and discussion with the practicing IT Managers, after assessing its reliability and validity. The instrument designed by Kraemer et al (2006) has been reviewed and critiqued by International Data Corporation's Global Research Organization and its global subsidiaries in the countries studied. Final instrument used for data collection was a structured non disguised structured questionnaire containing all close ended question with multiple choices.

In this research study, the internal consistency reliability of the instrument has been measured by applying Cronbach's alpha. Using Cronbach's Alpha $(\alpha)$, item wise reliability coefficient was found to be in the range of 0.7186 to 0.9142 , hence it appear to be acceptable. From Test -Retest method, same results was obtained on the two successive administrations of the instrument, and the reliability coefficient was found to be in the range of 0.7018 to 0.9225 . Hence the reliability of the instrument appeared to be acceptable.

Validity of the instrument has been tested by content and construct validity. Panel evaluations by 12 practicing managers (Subject Matter Experts) was done for assessing the content validity of the instrument. They were requested to access each item of the instrument. For all the measurement items, ten to eleven (out of twelve) subject matter experts rated the items as essential. Content Validity Ratio (CVR) for all measurement items have been found to be in the range of 0.667 to 0.833 . The mean CVR of items retained is the "content validity index" for the total test and it is 0.756 .

\section{Mean Content Validity Index for total test $=0.756$}

As, the mean CVR (which is 0.756 ) is positive and strong as it is closer to +1.0 . Hence the items in the instrument appears to have acceptable content validity.

For assessing the construct validity of the research instrument, Exploratory Factor Analysis method has been used. The result confirmed that the instrument exhibit satisfactory construct validity. The data was examined using principal components analysis as the extraction technique and Varimax with Kaiser normalization as the method of rotation. From the factor analysis it was found that, all the items have factor loading in excess of 0.7. Hence the result confirm that the instrument exhibit satisfactory construct validity.

\subsection{Data Analysis Procedure}

For identifying the problems in implementation of e-commerce in Kingdom of Saudi Arabia, a two phased process has been used. In the first phase, SPSS 16.0 Multiple Response Analysis techniques has been used to identify the various obstacles. The Multiple Response Analysis command allows to analyze a number of separate variables at the same time, and is best used in situations where the responses to a number of separate variables that have a similar coding scheme all 'point to' a single underlying variable. In this research, we have considered each of the items in the question as all pointing to the fact of negatively affecting e-commerce implementation. It helps in summarizing the responses to these items at once so that we can use the pattern of responses across these items in further analysis with other variables.

In the second phase, Hierarchical Multiple Regression Modeling (SPSS 16.0) has been used. It is an advanced variant of the basic multiple regression procedure that allows to specify a fixed order of entry for variables in order to control for the effects of covariates or to test the effects of certain predictors independent of the influence of others. Hierarchical Multiple Regression Modeling, a form of multi-level analysis, is a more advanced form of simple linear regression and multiple linear regression analysis that allows variance in outcome variables to be analyzed at multiple hierarchical levels.

\section{Results \& Discussion}

Various major obstacles / problems in the implementation of E-commerce in Kingdom of Saudi Arabia were identified through pilot survey. After the reliability and validity assessment of the instrument, full fledged survey was undertaken. Thirteen major obstacles were listed and the respondents were asked to evaluate these items according to their point of view. The question was "Using a 5-point scale, where 5 is "a very significant factor" and 1 is "not a factor at all," please rate, how much do the following obstacles affect your organizations ability to 
implement e-commerce solutions / do business online." Using SPSS 16.0 multiple response command, all these separate variables (multiple responses to above question) were analyzed and the important ones were identified. In the second part, Hierarchical Multiple Regression Modeling has been used to further analyze the variables to test their statistical significance.

In multiple response analysis, it has been observed that factors "concern for data security and privacy", "difficulty in integrating e-com software with the existing system", "lack of supporting business law" "small size of market for e-commerce", and "lack of skilled manpower" are the widely recognized problems /obstacles in implementing electronic commerce in Kingdom of Saudi Arabia. Table-1 shows the details on respondents answers to above question. Although the five barriers have been highlighted by the respondents in the survey, but it is possible that their identification is only due to chance and it has no statistical significance. Hence further statistical analysis is required to find out their statistical significance.

Table 1. Multiple response analysis (SPSS 16.0 Multiple Response Crosstabs Output)

\begin{tabular}{|c|c|c|c|c|}
\hline & & \multicolumn{2}{|c|}{ Responses } & \multirow{2}{*}{ Percent of Cases } \\
\hline & & Count & Percent & \\
\hline \multirow{13}{*}{ 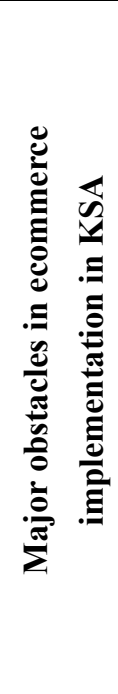 } & Lack of awareness of e-commerce & 120 & $7.0 \%$ & $50.6 \%$ \\
\hline & Limited knowledge of available technology & 44 & $2.6 \%$ & $18.6 \%$ \\
\hline & Lack of confidence in benefits of ecommerce & 65 & $3.9 \%$ & $27.8 \%$ \\
\hline & Shortage of skilled human resources & 171 & $10 \%$ & $72.2 \%$ \\
\hline & High cost of implementing ecommerce solution & 44 & $2.6 \%$ & $18.6 \%$ \\
\hline & Relatively small size of market for e-commerce & 185 & $10.9 \%$ & $78.1 \%$ \\
\hline & Lack of trust between customer and company & 154 & $9.0 \%$ & $65 \%$ \\
\hline & Lack of supporting business law for ecommerce & 206 & $12.1 \%$ & $86.9 \%$ \\
\hline & Insufficient infrastructure for e-commerce & 12 & $0.7 \%$ & $5.1 \%$ \\
\hline & Difficulty in integrating e-com with existing system & 192 & $11.3 \%$ & $81.0 \%$ \\
\hline & Resistance in adopting ecommerce & 101 & $5.9 \%$ & $42.6 \%$ \\
\hline & Concern for data security $\&$ privacy & 202 & $12.6 \%$ & $85.2 \%$ \\
\hline & Low return on investment & 101 & $5.9 \%$ & $42.6 \%$ \\
\hline
\end{tabular}

Table 2. SPSS Output of rating of the problems

\begin{tabular}{|c|c|c|c|c|c|}
\hline \multirow{2}{*}{$\begin{array}{l}\text { Major Problems in implementing } \\
\text { electronic commerce in KSA }\end{array}$} & \multicolumn{5}{|c|}{$\begin{array}{l}\text { Using a 5-point scale, where } 5 \text { is "a very significant } \\
\text { problem " and } 1 \text { is "not an obstacle at all," }\end{array}$} \\
\hline & 1 & 2 & 3 & 4 & 5 \\
\hline Lack of awareness of e-commerce & $50 \%$ & $35 \%$ & $15 \%$ & $00 \%$ & $00 \%$ \\
\hline Limited knowledge of available technology & $58 \%$ & $12 \%$ & $12 \%$ & $25 \%$ & $01 \%$ \\
\hline Lack of confidence in benefits of ecommerce & $50 \%$ & $21 \%$ & $20 \%$ & $09 \%$ & $00 \%$ \\
\hline Shortage of skilled human resources & $00 \%$ & $12 \%$ & $15 \%$ & $18 \%$ & $55 \%$ \\
\hline Cost of initial investment in adopting ecommerce & $54 \%$ & $22 \%$ & $12 \%$ & $07 \%$ & $05 \%$ \\
\hline Relatively small size of market for e-commerce & $00 \%$ & $10 \%$ & $10 \%$ & $32 \%$ & $48 \%$ \\
\hline Lack of trust between customer and company & $00 \%$ & $11 \%$ & $20 \%$ & $25 \%$ & $44 \%$ \\
\hline Lack of supporting business law for ecommerce & $00 \%$ & $04 \%$ & $08 \%$ & $51 \%$ & $37 \%$ \\
\hline Insufficient infrastructure for e-commerce & $70 \%$ & $20 \%$ & $10 \%$ & $00 \%$ & $00 \%$ \\
\hline Difficulty in integrating e-commerce with existing system & $00 \%$ & $00 \%$ & $12 \%$ & $10 \%$ & $78 \%$ \\
\hline Resistance in adopting ecommerce & $65 \%$ & $15 \%$ & $10 \%$ & $10 \%$ & $00 \%$ \\
\hline Concern for data security \& privacy & $00 \%$ & $05 \%$ & $07 \%$ & $20 \%$ & $68 \%$ \\
\hline Low return on investment & $00 \%$ & $12 \%$ & $19 \%$ & $19 \%$ & $50 \%$ \\
\hline
\end{tabular}


In order to further examine the statistical significance of these problems / obstacles in implementation of e-commerce in Kingdom of Saudi Arabia, Hierarchical Multiple Regression Modeling in SPSS has been used. It is a variant of the basic multiple regression procedure that allows to specify a fixed order of entry for variables in order to control for the effects of covariates or to test the effects of certain predictors independent of the influence of others. In this hierarchical regression analysis model, the variables have been named as given in Table-3.

Table 3. Variable description

\begin{tabular}{lll}
\hline & \multicolumn{1}{c}{ Dependent Variables } & Variable Indicator \\
\hline 1 & E-Commerce Implementation & ecom_implmnt \\
\hline 1 & \multicolumn{1}{c}{ Independent Variables } & Variable Indicator \\
2 & Lack of awareness of e-commerce & lack_awareness_ecom \\
3 & Lack of confidence in benefits of ecommerce & lmt_knowledge_tech \\
4 & Cost of initial investment in adopting ecommerce & lack_confidence_ecom \\
5 & Lack of trust between customer and company & highcost_imple_ecom \\
6 & Insufficient infrastructure for e-commerce & lack_trust_cust_company \\
7 & Resistance in adopting ecommerce & infrastructure_ecom \\
8 & Low return on investment & resistance_ecom_adption \\
9 & Relatively small size of market for e-commerce & lowreturn_investment \\
10 & Lack of supporting business law for ecommerce & small_market_ecom \\
11 & Concern for data security \& privacy & lack_busi_law_ecom \\
12 & Difficulty in integrating e-commerce with existing system & concern_data_security \\
13 & Shortage of skilled human resources & difficulty_integrating \\
\hline
\end{tabular}

The hierarchical regression model contains thirteen categories of independent variables (obstacles) hereafter referred as predictors. In this analysis, it has been examined to find out whether the five important problems/ obstacles (identified in the multiple response analysis - the last five variables shown in Table- 3) substantially contribute to obstacle in implementation of e-commerce in Kingdom of Saudi Arabia. At the same time it might be possible that other variables might be associated with obstacles in e-commerce implementation. To make sure that these variables do not explain away the entire association between the above mentioned predictors and obstacles in e-commerce implementation, all other predictors (other than the five selected predictors) have been put into the first model (Table-4). This ensures that they will get "credit" for any shared variability that they may have with the predictor that I am really interested in.

Table 4. Model summary

\begin{tabular}{|c|c|c|c|c|c|c|c|c|c|c|}
\hline \multirow[b]{2}{*}{ Model } & \multirow[b]{2}{*}{$\mathrm{R}$} & \multirow[b]{2}{*}{$\begin{array}{c}\mathrm{R} \\
\text { Square }\end{array}$} & \multirow[b]{2}{*}{$\begin{array}{c}\text { Adjusted } \\
\text { R } \\
\text { Square }\end{array}$} & \multirow{2}{*}{$\begin{array}{c}\text { Std. } \\
\text { Error of } \\
\text { the } \\
\text { Estimate }\end{array}$} & \multicolumn{5}{|c|}{ Change Statistics } & \multirow[b]{2}{*}{ Durbin-Watson } \\
\hline & & & & & $\begin{array}{c}\mathrm{R} \\
\text { Square } \\
\text { Change } \\
\end{array}$ & $\begin{array}{c}\mathrm{F} \\
\text { Change }\end{array}$ & df1 & $\mathrm{df} 2$ & $\begin{array}{l}\text { Sig. F } \\
\text { Change }\end{array}$ & \\
\hline 1 & $.144^{\mathrm{a}}$ & .021 & .032 & .40254 & .125 & 4.081 & 8 & 228 & .000 & \\
\hline 2 & $.355^{\mathrm{b}}$ & .126 & .091 & .40327 & .001 & .175 & 1 & 227 & .676 & \\
\hline 3 & $.403^{\mathrm{c}}$ & .163 & .126 & .39560 & .037 & 9.889 & 1 & 226 & .002 & \\
\hline 4 & $.414^{\mathrm{d}}$ & .171 & .131 & .39440 & .009 & 2.382 & 1 & 225 & .124 & \\
\hline 5 & $.415^{\mathrm{e}}$ & .172 & .128 & .39510 & .001 & .200 & 1 & 224 & .655 & \\
\hline 6 & $.422^{\mathrm{f}}$ & .178 & .130 & .39451 & .006 & 1.672 & 1 & 223 & .197 & 1.674 \\
\hline
\end{tabular}


a. Predictors: (Constant), lowreturn_investment, lmt_knowledge_tech, infrastructure_ecom, lack_confidence_ecom, lack_awareness_ecom, resistance_ecom_adption, lack_trust_cust_company, highcost_imple_ecom

b. Predictors: (Constant), lowreturn_investment, lmt_knowledge_tech, infrastructure_ecom, lack_confidence_ecom, lack_awareness_ecom, resistance_ecom_adption, lack_trust_cust_company, highcost_imple_ecom, small_market_ecom

c. Predictors: (Constant), lowreturn_investment, lmt_knowledge_tech, infrastructure_ecom, lack_confidence_ecom, lack_awareness_ecom, resistance_ecom_adption, lack_trust_cust_company, highcost_imple_ecom, small_market_ecom, lack_busi_law_ecom

d. Predictors: (Constant), lowreturn_investment, lmt_knowledge_tech, infrastructure_ecom, lack_confidence_ecom, lack_awareness_ecom, resistance_ecom_adption, lack_trust_cust_company, highcost_imple_ecom, small_market_ecom, lack_busi_law_ecom, concern_data security

e. Predictors: (Constant), lowreturn_investment, lmt_knowledge_tech, infrastructure_ecom, lack_confidence_ecom, lack_awareness_ecom, resistance_ecom_adption, lack_trust_cust_company, highcost_imple_ecom, small_market_ecom, lack_busi_law_ecom, concern_data security, shortage_skilled_hr

f. Predictors: (Constant), lowreturn_investment, lmt_knowledge_tech, infrastructure_ecom, lack_confidence_ecom, lack_awareness_ecom, resistance_ecom_adption, lack_trust_cust_company, highcost_imple_ecom, small_market_ecom, lack_busi_law_ecom, concern_data security, shortage_skilled_hr, difficulty_integrating

g. Dependent Variable: ecom_implmnt

Model-1 refers to the first stage in the hierarchy when first set of predictors are included in the model.

Model-2 refers to the second stage in the hierarchy when predictor "Small size of market for e-commerce" is considered as contributing to obstacles in ecommerce implementation.

Model-3 refers to the third stage in the hierarchy when set of predictors "Small size of market for e-commerce" and "Lack of supporting business law for ecommerce" are considered as contributing to obstacles in ecommerce implementation.

Model-4 refers to the fourth stage in the hierarchy when set of predictors "Small size of market for e-commerce", "Lack of supporting business law for ecommerce" and "Concern for cyber crime, data security \& privacy" are considered as contributing to obstacles in ecommerce implementation.

Model-5 refers to the fifth stage in the hierarchy when set of predictors "Small size of market for e-commerce", "Lack of supporting business law for ecommerce", "Concern for cyber crime, data security \& privacy" and "Shortage of skilled human resources" are considered as contributing to obstacles in ecommerce implementation.

Model-6 refers to the sixth stage in the hierarchy when set of predictors "Small size of market for e-commerce", "Lack of supporting business law for ecommerce", "Concern for cyber crime, data security \& privacy", "Shortage of skilled human resources" and "Difficulty in integrating e-commerce software with existing system" are considered as contributing to obstacles in ecommerce implementation.

The SPSS output in the form of Model Summary (Table-4) shows the percent of "variability in the dependent variable that can be accounted for by all the predictors together (that's the interpretation of R-square). In the column labeled $\mathrm{R}$ are the values of the multiple correlation coefficients between the predictors and the outcome. The next column gives a value of $\mathrm{R}^{2}$ which is a measure of how much of the variability in the outcome is accounted for by the predictors.

The change in $\mathrm{R}^{2}$ is a way to evaluate how much predictive power was added to the model by the addition of another variable in step 2 . In this case, the \% of variability in the outcome accounted for", went up from $4.7 \%$ to $26 \%$ - a substantial increase of more than $21 \%$.

The "Durbin-Watson statistic informs about whether the assumption of independent errors is tenable. The closer to that the value is, the better, and for these data the value is 2.431 , which is somewhat close to the value of adjusted $\mathrm{R}$ square, hence it can stated that the assumption has almost certainly been met.

ANOVA table (Table-5) reinforces our earlier findings as it tests the acceptability of the model from statistical perspective. Here all the models predicted scores on the Dependent Variable to a statistically significant degree as the significance values of all the models is less than 0.05 . Here it is important to note that value of $F$ defines the accuracy of the regression model. If the value of $F$ is greater than 1 then it can be interpreted that regression model overcomes the inaccuracy within the model and SPSS calculates the exact probability of obtaining the value of $F$ by chance. For the initial model the $F$ - ratio is 4.081 having the p-value of 0.070 . So it is not 
statistically significant. For the $2^{\text {nd }}$ model the F-ratio is 3.634 and it is highly unlikely to have happened by chance (as its p-value is less than 0.05). For the third model the value of $F$ is 4.388 , which is also highly significant $(p<0.05)$. The value of $F$ - ratio of fourth, fifth and sixth models are 4.230, 3.880 and 3.721 respectively and all of them are also highly statistically significant $(\mathrm{p}<0.05)$.

From these results it may be safely interpreted that the final model might count as significant to predict the outcome variable.

Table 5. ANOVA

\begin{tabular}{|c|c|c|c|c|c|c|}
\hline Model & & Sum of Squares & df & $\begin{array}{c}\text { Mean } \\
\text { Square }\end{array}$ & $\mathbf{F}$ & Sig. \\
\hline \multirow{3}{*}{1} & 5.291 & 8 & .661 & 4.081 & $.070^{\mathrm{a}}$ & \\
\hline & 36.945 & 228 & .162 & & & \\
\hline & 42.236 & 236 & & & & \\
\hline \multirow{3}{*}{2} & 5.319 & 9 & .591 & 3.634 & $.000^{\mathrm{b}}$ & \\
\hline & 36.917 & 227 & .163 & & & \\
\hline & 42.236 & 236 & & & & \\
\hline \multirow{3}{*}{3} & 6.867 & 10 & .687 & 4.388 & $.000^{\mathrm{c}}$ & \\
\hline & 35.369 & 226 & .157 & & & \\
\hline & 42.236 & 236 & & & & \\
\hline \multirow{3}{*}{4} & 7.237 & 11 & .658 & 4.230 & $.000^{\mathrm{d}}$ & \\
\hline & 34.999 & 225 & .156 & & & \\
\hline & 42.236 & 236 & & & & \\
\hline \multirow{3}{*}{5} & 7.269 & 12 & .606 & 3.880 & $.000^{\mathrm{e}}$ & \\
\hline & 34.968 & 224 & .156 & & & \\
\hline & 42.236 & 236 & & & & \\
\hline \multirow{3}{*}{6} & 7.529 & 13 & .579 & 3.721 & $.000^{\mathrm{f}}$ & \\
\hline & 34.707 & 223 & .156 & & & \\
\hline & 42.236 & 236 & & & & \\
\hline
\end{tabular}

a. Predictors: (Constant), lowreturn_investment, lmt_knowledge_tech, infrastructure_ecom, lack_confidence_ecom, lack_awareness_ecom, resistance_ecom_adption, lack_trust_cust_company, highcost_imple_ecom

b. Predictors: (Constant), lowreturn_investment, Imt_knowledge_tech, infrastructure_ecom, lack_confidence_ecom, lack_awareness_ecom, resistance_ecom_adption, lack_trust_cust_company, highcost_imple_ecom, small_market_ecom

c. Predictors: (Constant), lowreturn_investment, Imt_knowledge_tech, infrastructure_ecom, lack_confidence_ecom, lack_awareness_ecom, resistance_ecom_adption, lack_trust_cust_company, highcost_imple_ecom, small_market_ecom, lack_busi_law_ecom

d. Predictors: (Constant), lowreturn_investment, Imt_knowledge_tech, infrastructure_ecom, lack_confidence_ecom, lack_awareness_ecom, resistance_ecom_adption, lack_trust_cust_company, highcost_imple_ecom, small_market_ecom, lack_busi_law_ecom, concern_data_security

e. Predictors: (Constant), lowreturn_investment, $1 \mathrm{mt}$ _knowledge_tech, infrastructure_ecom, lack_confidence_ecom, lack_awareness_ecom, resistance_ecom_adption, lack_trust_cust_company, highcost_imple_ecom, small_market_ecom, lack_busi_law_ecom, concern_data_security, shortage_skilled_hr

f. Predictors: (Constant), lowreturn_investment, lmt_knowledge_tech, infrastructure_ecom, lack_confidence_ecom, lack_awareness_ecom, resistance_ecom_adption, lack_trust_cust_company, highcost_imple_ecom, small_market_ecom, lack_busi_law_ecom, concern_data_security, shortage_skilled_hr, difficulty_integrating g. Dependent Variable: ecom_implmnt 
The next part of the SPSS 16.0 output (Table-6) is concerned with the parameters of the model.

Table 6. Coefficients for the sixth (final) model

\begin{tabular}{llllll}
\hline \multicolumn{1}{c}{$6^{\text {th }}$ Model } & \multicolumn{2}{l}{ Unstandardized Coefficients } & $\begin{array}{l}\text { Standardized } \\
\text { Coefficients }\end{array}$ & t & Sig. \\
& $\mathrm{B}$ & Std. Error & Beta & \\
\hline (Constant) & 1.512 & .558 & & 2.708 & .007 \\
lack_awareness_ecom & .184 & .065 & .018 & 2.829 & .085 \\
lmt_knowledge_tech & -.053 & .086 & -.049 & -.612 & .541 \\
lack_confidence_ecom & .029 & .078 & .031 & .378 & .706 \\
highcost_imple_ecom & -.206 & .118 & -.190 & -1.753 & .081 \\
lack_trust_cust_company & .011 & .090 & .013 & .125 & .900 \\
infrastructure_ecom & .003 & .130 & .001 & .021 & .983 \\
resistance_ecom_adption & .038 & .074 & .044 & .505 & .614 \\
lowreturn_investment & .038 & .107 & .040 & .356 & .722 \\
small_market_ecom & .271 & .085 & .531 & -.199 & .302 \\
lack_busi_law_ecom & .260 & .105 & .529 & 2.487 & .014 \\
concern_data_security & .161 & .090 & .158 & 1.794 & .024 \\
shortage_skilled_hr & .028 & .076 & .350 & -.365 & .125 \\
difficulty_integrating & .043 & .033 & .388 & 1.293 & .027 \\
\hline
\end{tabular}

Here it more important to look at the final model because it includes all predictors that make a significant contribution to predicting relationship between predictors and inefficient E-Commerce in Kingdom of Saudi Arabia. In SPSS 16.0 output, the notation "Beta" is used to refer to Standardized Coefficients while notation "B" is used to refer to Unstandardized coefficients. The standardized regression coefficients, represent the change in terms of standard deviations in the dependent variable (that is implementation of e-commerce in KSA) that result from a change of one standard deviation in an independent variables, mentioned in hierarchy of models.

The B values tell us about the relationship between inefficient and each predictor. If the value is positive it can tell that there is a positive relationship between the predictor and the outcome whereas a negative coefficient represents a negative relationship. Each of these beta values has an associated standard error indicating to what extent these values would vary across different samples. Therefore, if the t-test associated with a B value is significant (if the value in the column labeled sig. is less than 0.05 ) then that predictor is making a significant contribution to the model.

Here it clear from the output that for the final model (Table-6), lack of supporting business law (lack_busi_law_ecom, $\mathrm{t}=2.487, \mathrm{p}<0.05$ ), concern for data security $\&$ privacy (concern_data_security, $\mathrm{t}=1.794$, $\mathrm{p}<0.05$ ) and difficulty in integrating ecommerce software with existing system (difficulty_integrating, $\mathrm{t}=1.293$, $\mathrm{p}<0.05$ ) are statistically significant in terms of contribution to obstacles in e-commerce implementation as their p-value is lower than 0.05 while "Shortage of skilled human resources" and "Small size of market for e-commerce" are not statistically significant as their significance value is higher than 0.05 . Besides, as the standardized beta values $(\beta)$ are measured in standard deviation units and hence they are directly comparable. Due to this, they provide a better insight into the "importance of predictor in the model. In this model out of the five predictors, "Lack of supporting business law for ecommerce", "Concern for cyber crime, data security \& privacy", and "Difficulty in integrating e-commerce software with existing system" are having positive standardized Beta values which proves that they affect the implementation of ecommerce while both "Shortage of skilled human resources" and "Small size of market for e-commerce" are having negative standardized Beta values and hence they may be considered as statistically non significant in contributing to obstacle in ecommerce implementation . 


\section{Conclusion}

Following conclusion may be drawn from the SPSS 16.0 output for hierarchical regression modeling confirms for all the GCC nations. From the Multiple Response Analysis and Hierarchical Regression Modeling of data obtained through survey, it has been found that the major problem in implementing e-commerce is because of following obstacles.

- Lack of supporting business law for ecommerce

- Concern for cyber crime, data security \& privacy

- Difficulty in integrating e-commerce with existing system

Based on the value of $\mathrm{R}^{2}$ which is a measure of how much of the variability in the outcome is accounted for by the predictors and the Durbin-Watson statistic value is 2.431 , which is somewhat closer to the value of adjusted $\mathrm{R}$ square, hence it can stated that the assumption has almost certainly been met. As a rule of thumb, Durbin Watson test statistics value in the range of "more than 1 " to "less than 3 " is acceptable. Hence the obtained value of Durbin-Watson statistic (which is 2.431), is well within the acceptable range.

From the analysis output it is clear that out of the five predictors, "Lack of supporting business law for ecommerce", "Concern for cyber crime, data security \& privacy", and "Difficulty in integrating e-commerce software with existing system" are having positive standardized Beta values which proves that they affect the implementation of ecommerce in Kingdom of Saudi Arabia. In the survey, it has been found that lack of supporting business law for adopting and implementing ecommerce has also been cited as another major obstacle in KSA. In KSA, more than $80 \%$ of the business establishments face the obstacle of absence of supporting business laws in implementation of e-commerce. It assumes greater significance because of the fact that cyber crimes are picking up pretty fast in this part of the world.

Hence it can be safely concluded that the above mentioned three predictors are statistically significant and major contributors in obstacles for e-commerce implementation in Kingdom in Saudi Arabia.

\section{Implication for Future Research}

As the major thrust area of this research study is statistical analysis of problems in e-commerce implementation at the macro level. This study is more horizontal in terms of topical dimension. Hence it highly appropriate if in future an in depth study is carried out to do more precise micro level analysis on case to case basis. Another important area in which future research is needed is to find out whether some of the problems identified here has any significant relation with the other parameters viz. size of the firm or business nature of the firm. A substantial research effort is needed to examine the differences in problems in implementation of e-commerce by start-up firms and large multi national firms.

\section{Implication for Managers}

As three major problems have been identified and found to be statistically significant in implementation of e-commerce in KSA, a closer look at these problems clearly reflect its managerial significance. Problem "Difficulty in integrating e-commerce software with existing system" can best be handled at organizational level as the solution of this problem can be initiated within the organization with relevant outside technical assistance. Another problem "Concern for cyber crime, data security \& privacy" again can only be handled and solved by the strengthening of the cyber frontier of the firm by the ever evolving and off the shelf readily available technological tools and techniques which can be customized accordingly.

\section{References}

(n.d.). Saudi Arabian General Investment Authority: The hard facts. Retrieved from http://www.sagia.gov.sa/en/Why-Saudi-Arabia/The-hard-facts

Al-Hudhaif, S., \& Alkubeyyer, A. (2011). E-Commerce Adoption Factors in Saudi Arabia. International Journal of Business and Management, 6(9).

Begin, L., \& Boisvert, H. (2002). The Internal Factors that Can make or Break E-commerce Implementation. (Special Focus on E-business Strategies). CMA Management, April, 22-25.

Howitt, D., \& Cramer, D. (2008). Introduction to SPSS in Psychology: For Version 16 and earlier (4 $4^{\text {th }}$ ed.). Harlow: Pearson.

Kraemer, K.L., Melville, N.P., Zhu, K., \& Dedrick, J. (2006). Global e-commerce: Impacts of National Environment and Policy. Cambridge, New York, Cambridge University Press, pp. 389-402. 
Miaoulis, G., \& Michener, R. D. (1976). An Introduction to Sampling. Dubuque, Iowa: Kendall/Hunt Publishing Company.

OECD. (2005). Working Party on Indicators for the Information Society. Retrieved from http://www.oecd.org/dataoecd/41/12/36177203.pdf

Oreku, G.S., Mtenzi, F.J., \& Ali, A.D. (2011). The Prospects and Barriers of E-Commerce Implementation in Tanzania. Paper presented at ICIT $5^{\text {th }}$ International Conference on Information Technology, Amman, Jordan, 11-13 May.

Radovilsky, Z., \& Hegde, V. G. (2004). Factors influencing e-commerce implementation: Analysis of urvey results. Journal of Academy of Business and Economics, 4(1), 29-37.

Radovilsky, Z., \& Hegde, V.G. (2004). Factors influencing e-commerce implementation: Analysis of survey results. Journal of Academy of Business and Economics, 4(1), 29-37.

Teo, T.L., Chan, C., \& Parker, C. (2004). Factors Affecting e-Commerce Adoption by SMEs: A Meta- Analysis. ACIS 2004 Proceedings. Paper 54.

The Rand Corporation. (1955). A Million Random Digits with 100,000 normal deviates. Glencoe, IL: Free Press. p. 225.

Yamane, T. (1967). Statistics, An Introductory Analysis ( ${ }^{\text {nd }}$ Ed). New York: Harper and Row, p58.

Zhu, K. (2004). E-Commerce Capability: A Resource-Based Assessment of Their Business Value. Journal of Management Information Systems, 21(1), 167-202. 